\title{
Exfoliative vaginal cytology during the oestrous cycle of West African dwarf goats
}

\author{
Safiriyu Idowu OLA ${ }^{\mathrm{a} *}$, Waliu Ajani SANNI ${ }^{\mathrm{a}}$, Gabriel EGBUNIKE ${ }^{\mathrm{b}}$ \\ a Department of Animal Science, Obafemi Awolowo University, Ile-Ife, Nigeria \\ ${ }^{b}$ Department of Animal Science, University of Ibadan, Ibadan, Nigeria
}

(Received 4 April 2005; accepted 14 October 2005)

\begin{abstract}
The pattern of vaginal cell exfoliation during the oestrous cycle period was studied in cycling and non-descript West African dwarf (WAD) goats. The exfoliated epithelial cells were categorised into parabasal, intermediate and superficial and their relative occurrences were used to determine the reproductive status of the cycling and non-descript does. The mean cell counts of the epithelial and leucocyte cells were also compared between the days of cycle. Leucocyte and epithelial cells were present in the vaginal smears of the WAD does throughout the cycle. Cell counts increased sharply on days 1 and 2 after standing oestrus. From day 4 of the cycle, the counts fell back to the levels at oestrus and daily variations thereafter were not striking enough to distinguish between the different stages of the cycle. In the non-descript does, the intermediate cell dominated the majority of the smears, which is the typical pattern of cell exfoliation in anoestrus and peri-pubertal does. In the smears from cycling does, however, superficial cells were more frequently observed and they appeared to be associated with the proestrus, oestrus and early metoestrus phases of the cycle. These results indicate that the pattern of exfoliation of vaginal cells could be used to determine the reproductive condition and by extension the ovarian functioning of the WAD goats.
\end{abstract}

WAD goat / vaginal cytology /oestrous cycle

\section{INTRODUCTION}

In the normal cycling female livestock, morphologic, endocrine and secretory changes occurring in the ovaries and the tubular genitalia during the oestrous cycle usually depict the stage of the cycle. These changes have been associated with levels of steroid sex hormones. In the absence of infections, the circulating levels of progesterone and oestradiol-17 $\beta$ are the major determinants of the cytology pattern of the vagina [1, 2]. However Perez-Martinez et al. [2] showed that oestrone is the main oestrogen produced during the peripuberal period of the goat and it remains detectable in adult goats even after progestagen treatment when serum oestradiol was not detected. Exfoliated cells in the vaginal lumen are the result of rising peripheral oestrogen which causes the vaginal wall to thicken. As the outermost layer moves further from the vascular supply, the cells keratinise and detach from the wall. Thus, the exfoliated cells are a normal occurrence during the oestrous (and menstrual) cycle of animals (and women). What has been found very useful is the morphology of the exfoliated

\footnotetext{
* Corresponding author: sola@oauife.edu.ng
} 
cells, which has been utilised to determine the physiological and pathological status of the female animal as well as a tool for hormonal bioassay in several animal species [2-6].

The African dwarf goat is found domesticated in every continent, including the temperate regions and this may not be unconnected with the opinion of the National Research Council [7] that the dwarf goat, as a miniature goat, is potentially desirable for biomedical research. The dwarf goat is also a cheaper source of meat in many of the tropical countries where they are found. There is scanty information available on the Exfoliative Vaginal Cytology (EVC) of these goats [8, 9]. Parer [9] studied the vaginal content of six African dwarf goats and reported that both epithelial cells and leucocytes were present in the smear throughout the cycle. The epithelial cells were spherical but an increasing number of desquamated and cornified epithelial cells appeared between days 1 and 5 after oestrus. On the first day of appearance of the desquamated cells, leucocytes were either absent or in a small number in $67 \%$ of the cycles observed. Thereafter, the number increased and sometimes appeared in great number until the next appearance of the desquamated cells. Parer [9] also reported that the quantity of vaginal smear, using an arbitrary scale, was the greatest between days 0 and 2 of the cycle and a maximum occurrence of cheesy white appearance. The observation of Akusu [8] on the West African dwarf (WAD) goats is similar to that of Parer [9]. He also estimated on an arbitrary scale, the percentage occurrence of the leucocytes and epithelial cells in the smear to be 55 and $45 \%$, respectively on day 1 (oestrus), leucocytes were more prevalent on days 2 and 3 (early metoestrus) while the spherical epithelial cells were more prevalent on days 4 and 5 (late metoestrus). On other days of the cycle (dioestrus), there were only slightly more leucocytes than epithelial cells. Despite these two reports, details about the EVC of dwarf goats are still lacking. In our study reported in this paper, we sought to expatiate upon the information available on the EVC of the dwarf goats. Our aim was to determine the usefulness of EVC to evaluate the reproductive status of the WAD does.

\section{MATERIALS AND METHODS}

\subsection{Animals and management}

Eleven WAD does were employed in two separate trials. Three of the does were used during both trials. The does were intensively managed, zero-grazed ad libitum on a combination of Panicum maximum, Gliricidia sepium and Leucanea leucocephala with concentrate supplementation at $150 \mathrm{~g} / \mathrm{head} /$ day. Water was supplied daily. The two trials were carried out during the late rainy months of August and September, 2002 (trial 1) and the dry months of March and April 2003 (trial 2), both under the tropical humid condition of the Obafemi Awolowo University Teaching and Research Farm, Ile-Ife, Nigeria. The animals were housed individually in concrete floored pens.

\subsection{Trial 1}

Three normo-cycling and three nondescript pubertal does were used to study the morphology of the exfoliated cells. The non-descript does were over a year old and weighed 8,11 and $15 \mathrm{~kg}$. They, however, had bad reproductive records and their reproductive status was not known at the beginning of the study. The normo-cycling does, however, weighed 13, 13 and $16 \mathrm{~kg}$ and were observed for one natural unsynchronised oestrous cycle. At the exhibition of second oestrus, a vaginal smear was collected from each doe at 2 or 3 day intervals over a 60 day period. Smears were also collected from the non-descript does at the same period without prior exhibition of oestrus. The smear collection procedure involved parting the vulva lips and inserting a $10 \mathrm{~cm}$ long cotton-tipped sterile swab into the vagina to a depth of about $5-7 \mathrm{~cm}$. The 
swab still inside the vagina was rotated through 2-3 revolutions against the vaginal wall. The swab was withdrawn and rolled on a clean glass slide to form two parallel tracks of smear material on the glass surface. The smear was immediately fixed in absolute methanol, air-dried and stained with the Leishman stain. The epithelial cells were classified under a light microscope into superficial, intermediate and parabasal using the Grunert criterion [10]. From ten different fields, each cell type was counted and then expressed as a percentage of total. On smear sampling days, smear collection was always done between 0800 and $1000 \mathrm{~h}$ at which period oestrus was also checked in the does just prior to smear collection. Oestrus was checked with an intact but aproned buck. Standing to be mounted by the buck was used as the only confirmatory sign of oestrus.

\subsection{Trial 2}

This experiment was aimed at quantifying the exfoliated epithelial cells and the leucocyte cells in the vaginal smears of the goats using the simple haemocytometer counter method. This was based on previous observations $([8,9]$ and trial 1$)$ that both cell types are seen in the smear throughout the oestrous cycle of dwarf goats. The three normocycling does in trial 1 and another five adult WAD does were first observed to cycle normally without artificial synchronisation for two oestrous cycles. At the third oestrus exhibition, vaginal content of each doe was collected with a sterile cottontipped swab inserted into the vagina as described in trial 1 . This was repeated every morning thereafter for one cycle length. After withdrawing the swab from the vagina, the smeared end of the swab was rinsed with $4 \mathrm{mLs}$ of distilled water into a glass tube. Using a suction pipette, a few drops of the fluid were charged unto the haemocytometer chamber. Epithelial and leucocyte cells within 5 large squares of the chamber were counted separately under a light microscope. The number of cells in
$1 \mathrm{~mm}^{3}$ of diluted smear was calculated as $2 \mathrm{~N}$ where $\mathrm{N}$ is the sum of the cells within the 5 chambers (i.e. $1 / 2 \mathrm{~mm}^{3}$ ). Oestrus was checked daily in all the 8 unsynchronised animals with an aproned buck just before smear collection until standing oestrus was detected.

\subsection{Statistical analyses and representation}

In trial 1, each smear was evaluated separately and each cell type is reported as a percentage of total cell count in that smear. Each smear is represented with a grouped bar generated with SigmaPlot 2000 [11] software. All the smears from a single animal are represented on a single graph while all three animals in a group (normocycling or non-descript) are presented on a figure. In trial 2, the daily (day of the cycle) mean of the epithelial cell and leucocyte counts of the 8 does was calculated and compared between the days of cycle using the ANOVA procedure of SAS 2000 [12] software. The epithelial and leucocyte cell counts in the individual doe are also expressed as the percentage of total cell count for that particular smear and represented with grouped bars using SigmaPlot 2000 software.

\section{RESULTS}

\subsection{Trial 1: exfoliated cell characterisation}

Figure 1 shows the percentages of different epithelial cells in the vaginal smears of non-descript WAD does. Smears could not be collected between days 16 and 22 due to technical hitches. Amongst the total 69 smears collected, $90 \%$ showed a preponderance of intermediate epithelial cells. The percentage occurrence of the intermediate cells ranged from 5-100\%. The superficial cells were noted in 46 smears $(66.7 \%)$ with an occurrence varying from $1-95 \%$. Standing oestrus behaviour was detected (day 9 in doe 5732) on only one of these occurrences and only $28 \%$ of the total epithelial 


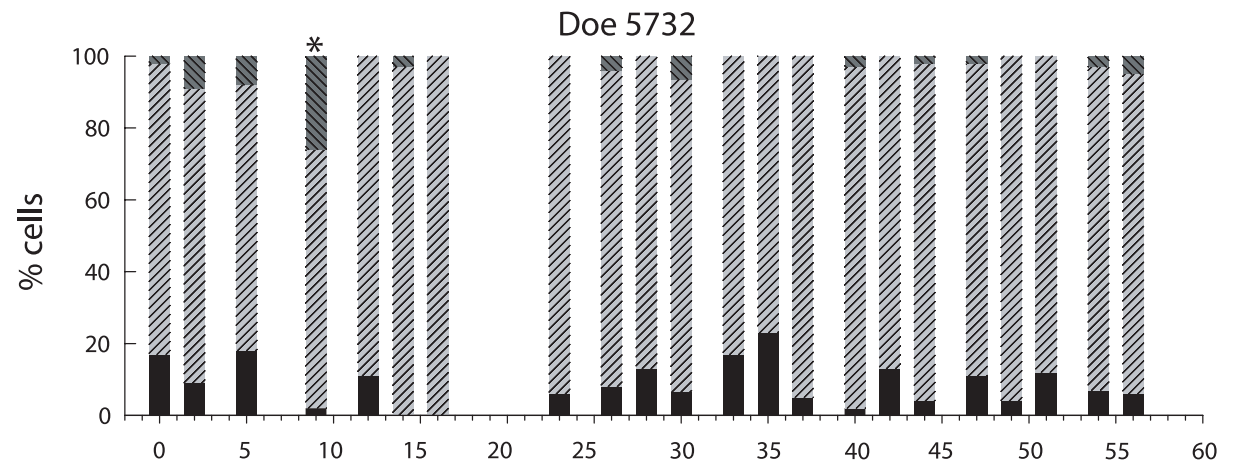

Doe 5657
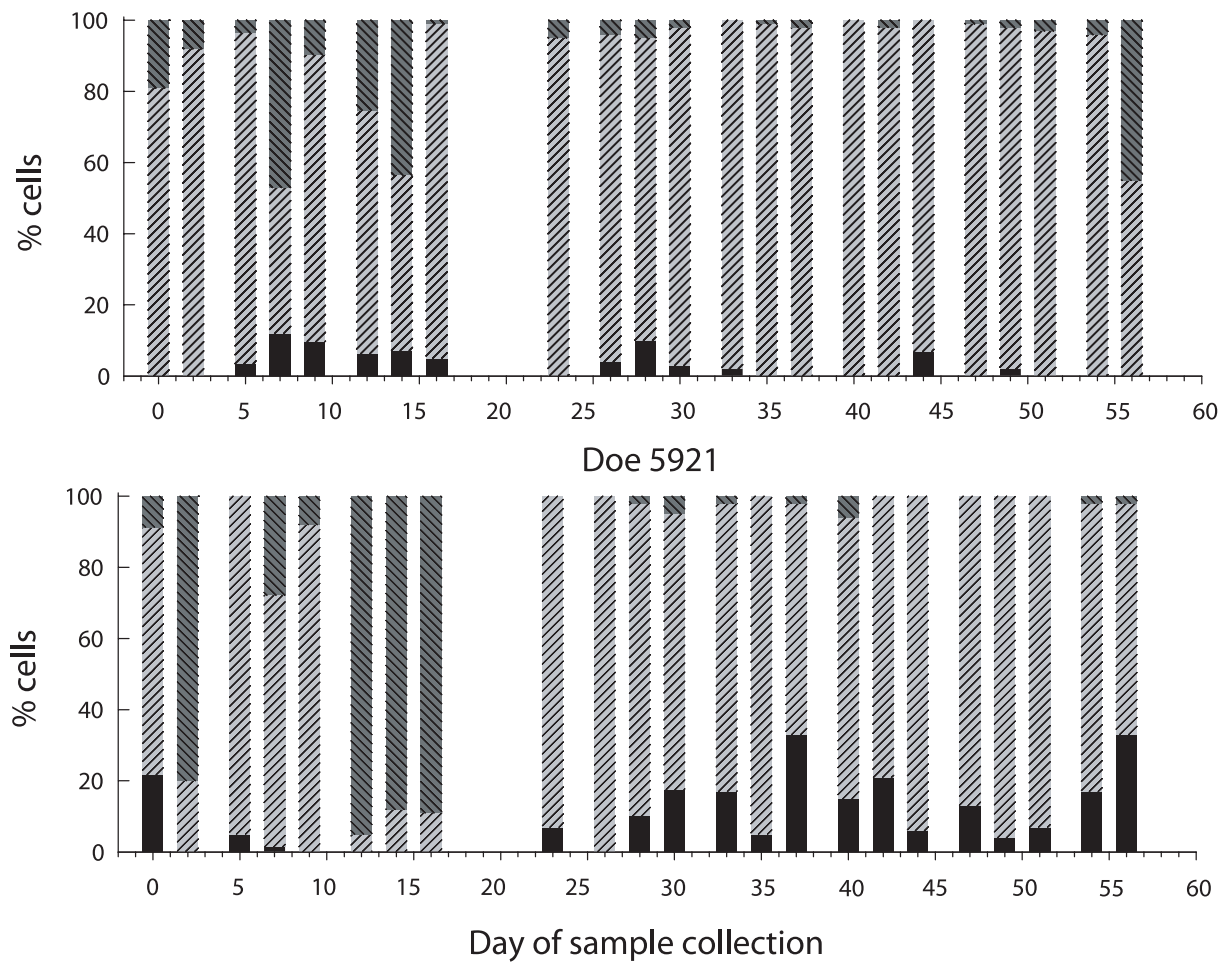

Figure 1. Percentages of parabasal, intermediate VIIIIA and superficial wW epithelial cells in the vaginal smear of three non-descript WAD does. The asterisk above the bar indicates detection of standing oestrus behaviour.

cells in that smear were superficial cells. The parabasal cells occurred at relatively lower percentages of $1.5-33 \%$ in $49(71 \%)$ smears. Figure 2 shows the occurrence of different epithelial cells in the adult cycling does. Samples were missed between days 6 and 13,11 and 18 , and 9 and 16 in does 1194 , 1001 and 1005 respectively. As in the nondescript does, the intermediate cells dominated in the majority $(80.6 \%)$ of the smears. 

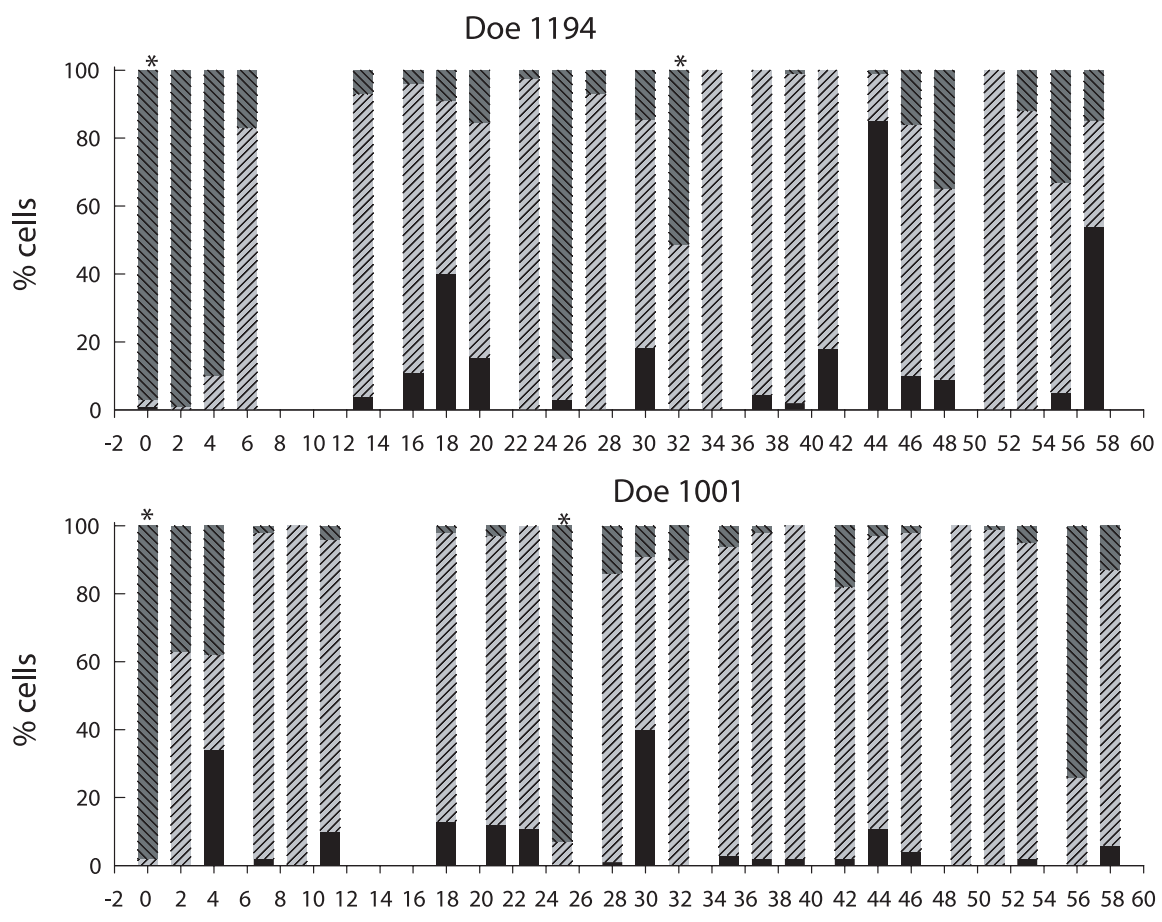

Doe 1005

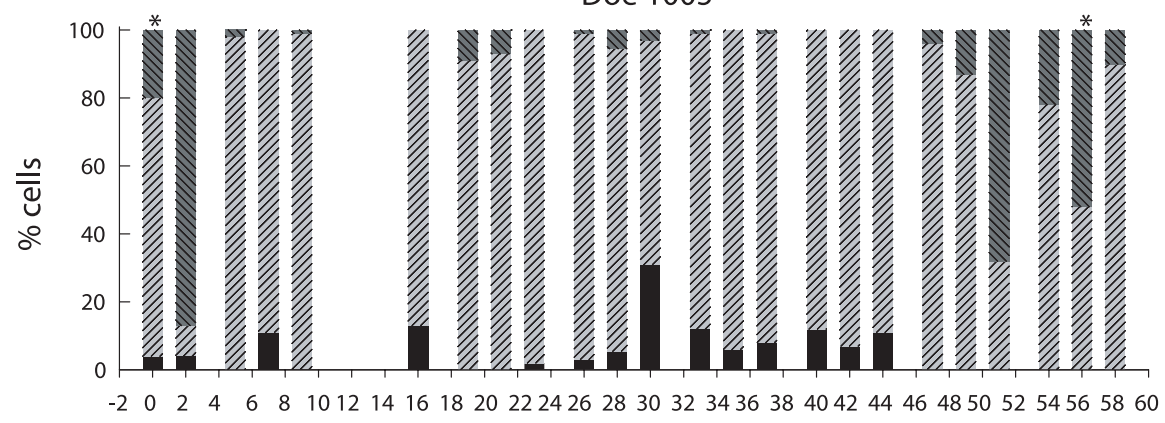

Day of sampling

Figure 2. Percentages of parabasal intermediate $y / I I I /$ and superficial www epithelial cells in the vaginal smears of three adult cycling WAD does. The asterisk above the bars indicates detection of standing oestrus behaviour.

However, the superficial cells appeared more frequently than the parabasal cells. Amongst 57 (79.2\%) smears on which superficial cells were seen, 6 were associated with standing oestrus detection. The superficial cells accounted for between 20-97\% of the epithelial cells on such smears.

\subsection{Trial 2: exfoliated cell quantification}

Epithelial and leucocyte cells were present in all, but one (day 10, doe 1001) of the 119 smears obtained from the 8 does during one oestrous cycle. The mean cell counts showed that the two types of cells 


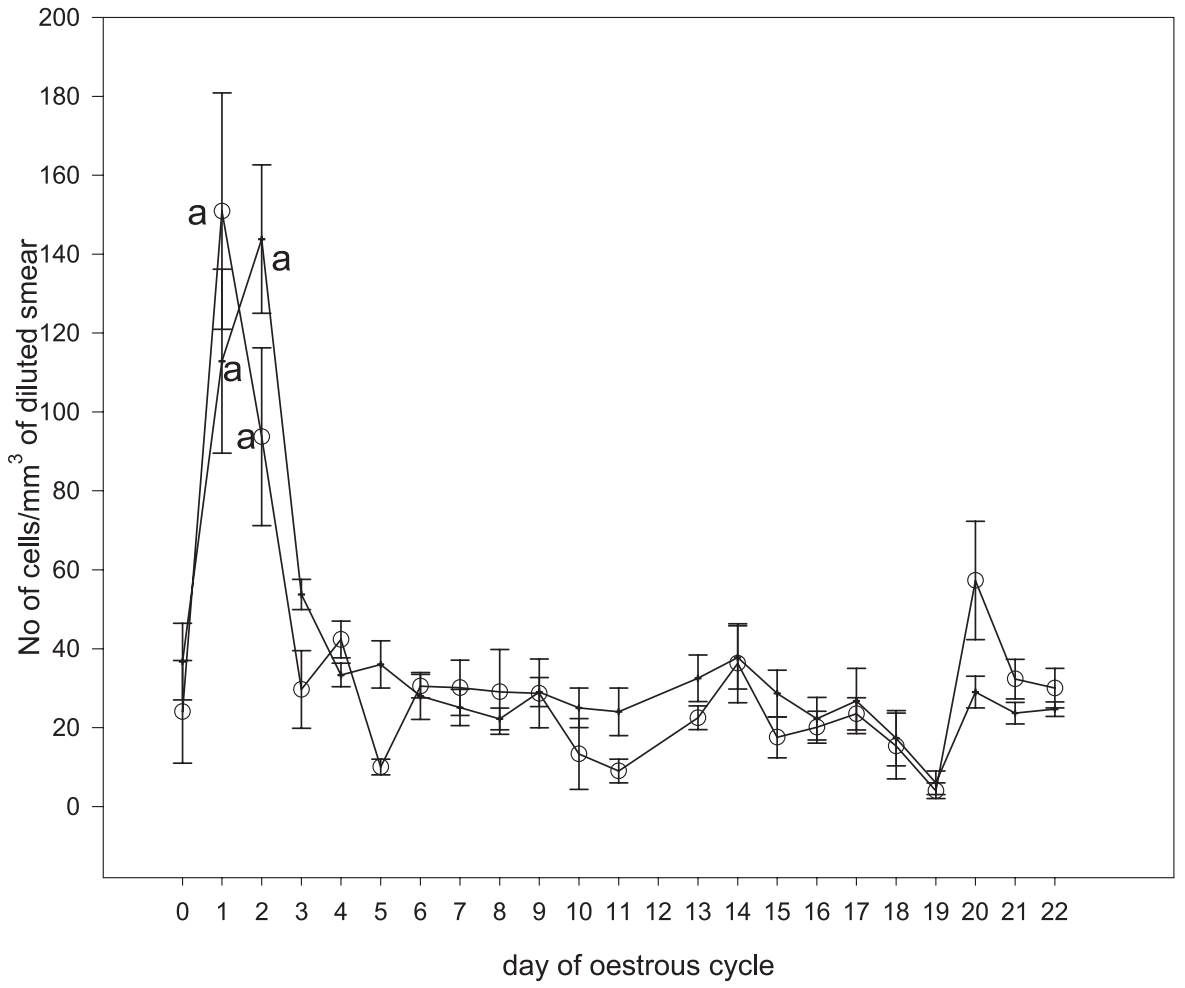

Figure 3. Exfoliated vaginal cell counts in WAD does during one oestrous cycle. ${ }^{a}$ The labelled points are significantly different $(P<0.05)$ from others on the same curve. $\bigcirc$ leucocyte cell; + epithelial cell.

were present in similar numbers and they also exhibited some kind of positive association (Fig. 3). Both the epithelial and leucocyte cell counts increased significantly $(P<0.05)$ and sharply on days 1 and 2 after standing oestrus (day 0 ). The cell counts then dropped back, and sharply too, on day 3 to a level similar to that of oestrus (day 0 ) and further variations until day 22 did not show significant rise or depression on the curve. The cell counts expressed as percentages of the total count for the 8 individual does are represented with grouped bars in Figure 4. The smears were supposed to be collected daily during one normal cycle period, i.e. 19-22 days. However some days were lost to technical constraints and an empty bar was used to represent those days on the graphs.

One of the does (No. 1082) exhibited an 11-day (short) cycle during the experiment while the remaining seven exhibited medium (regarded as normal) cycle lengths of between 19-22 days [8, 13]. Amongst the 119 smears from the 8 does, $19(16 \%)$ of them represented the day of standing oestrus. In $58 \%$ of the smears collected on these days, epithelial cells contributed more than half of the total cell count while the leucocytes dominated in only $26 \%$ of the smears, with the remaining $21 \%$ containing both cells in equal proportion. In 6 of the 8 does, smears collected on day 1 i.e. the day after the first oestrus day, showed an increase in 

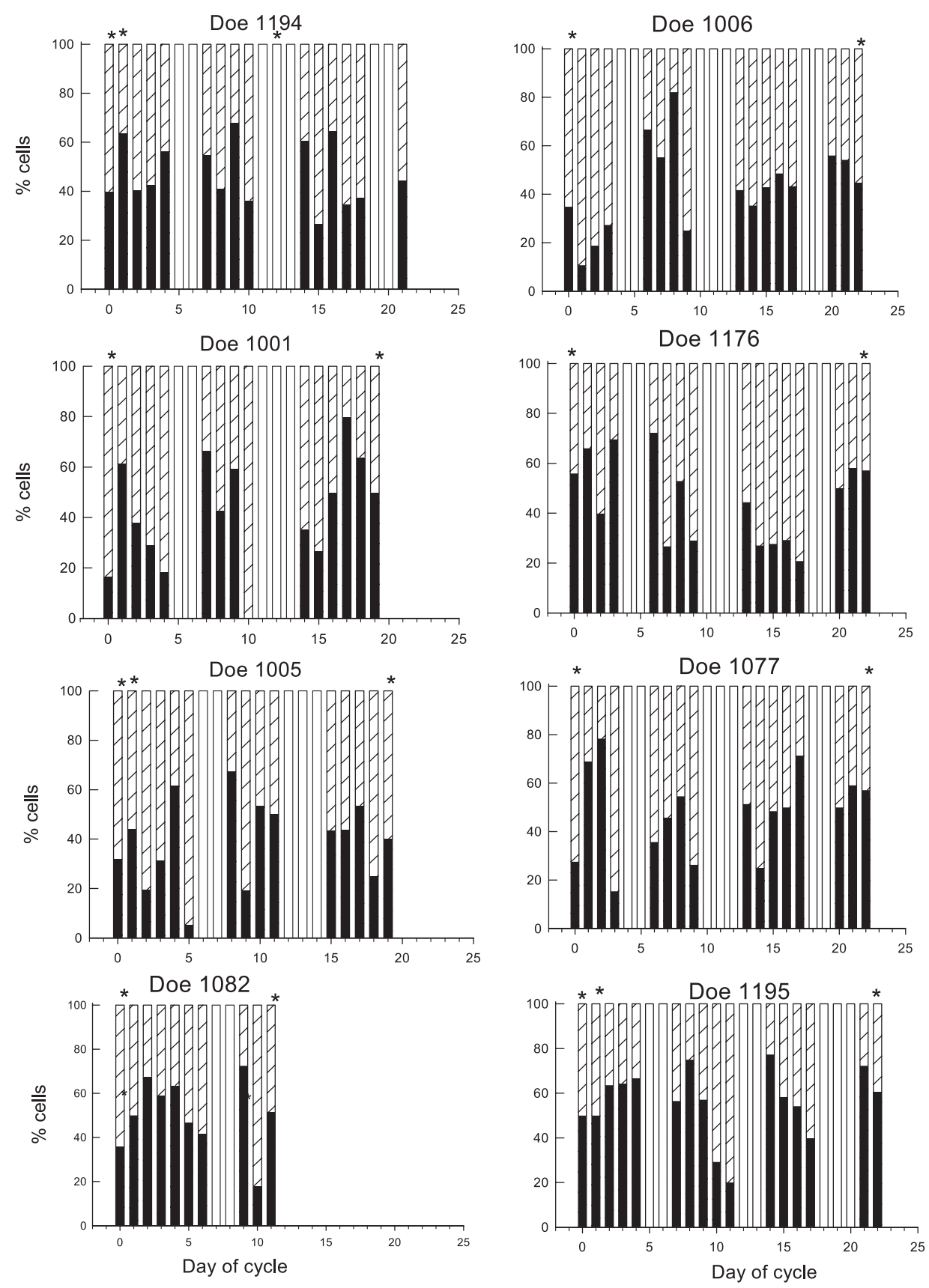

Figure 4. Percentages of leucocytes

WAD does. The asterisks above the bars indicate the day of standing oestrous behaviour. 
the proportion of leucocytes. There was a further increment of the leucocyte $\%$ on day 2 over day 1 in $50 \%$ of the does.

\section{DISCUSSION}

In the cycling does, superficial cells appeared to be associated with the proestrus, oestrus and early metoestrus phases. These phases are oestrogen controlled and are known to be characterised by high concentrations of endometrial cytoplasmic oestrogen receptors in response to the high circulating oestrogen from the pre-ovulatory and newly ovulated Graafian follicles [14]. The intermediate and parabasal cells were more conspicuous in the smears from other days i.e. dioestrus which correspond to the luteal phase controlled by progesterone. These cyclical relationships between the exfoliated cells and the ovarian steroids have been severely established for small ruminants and other species $[2,3,6]$. The average cycle length for the does during trial 1 could not be determined because the smears were not collected on a daily basis. Also oestrus was checked only in the morning of days when smears were collected hence some of the oestrus days might have been missed, because normal oestrus in WAD goats could sometimes last for only about $12 \mathrm{~h}$ commencing anytime during the day $[8,15]$. This would explain why only few standing oestrus days were observed during trial 1 . The smears from the nondescript does were dominated by small and large intermediate cells and there were few occurrences of parabasal and superficial cells. Only on one occasion was standing oestrus detected (day 9, doe 5732). Since large intermediate cells dominated the smear on this day, it could have just been the early hours of oestrus, because oestrus behaviour is usually associated with a preponderance of superficial (desquamated or cornified) cells $[2,3,7,8,10]$. The vaginal cytological pattern of the non-descript does in this study was typical of anoestrus and peri-pubertal does $[2,3]$. The smears from the adult (supposedly normocycling) does indeed showed some evidence of regular cycling. Even though oestrus was not detected at regular intervals, the intermittent occurrences of the superficial cells could indicate short, medium or long cycle length. A better picture could have been painted if the smears were collected daily or the oestrus checked daily and more intensely.

The observation of epithelial cells and leucocytes in the vaginal smears throughout the oestrous cycle of the WAD goats in this study was consistent with the findings of Akusu [8] and Parer [9]. The leucocytes were of the polymorphonuclear type throughout the smears. The sharp increase in the count of exfoliated and leucocyte cells during the early metoestrus (day 1-3) could be attributed to swabs picking up more cells as a result of the increased vaginal mucus secretion during this period. This increased secretion has been observed to persist in some goats till day 5 postoestrus with the consistency and appearance being more cheesy and whitish $[8,9$, 16]. These authors assumed that increased infiltration of leucocytes across the vaginal epithelium into the lumen was responsible for the cheesy-white appearance during this period. We equally observed in our study that more polymorphonuclear leucocyte cells were observed in smears with heavy cheesy materials obtained mainly in the metoestrus period. Larsen et al. [4] had reported a positive association between the cornified and leucocyte cells in the vagina of the rat and proposed that the influx of the leucocytes could be a response to the increased bacterial flora associated with the cornified desquamated cells of the oestrus phase. This proposition was based on their observation that when leucocytes were present in the vagina they were 90 to $100 \%$ viable and their number (leucocyte count) was inversely related to that of bacterial count in the same vaginal lumen. Thus, apart from the increased vaginal secretion mentioned earlier, the sudden rise in the leucocyte counts that was observed on days 1 and 2 of the cycling goats in trial 2 could be a response to an increase in 
bacterial flora accompanying the increased superficial cells of oestrus and early metoestrus. The increased percentage of the leucocyte cells relative to the epithelial cells on day 1 in $75 \%$ of the does in Figure 4 was consistent with this finding. The variations observed in the counts of the epithelial and leucocyte cells from the late metoestrus, day 4, until the next oestrus were not striking enough to distinguish between the end of dioestrus and the beginning of next oestrus. This could be due to the fact that the does came into oestrus at different times between days 19 and 22 . This means that the length of the dioestrus period varied in the does. Similarly, the variations observed in the percentage contributions of the epithelial and leucocyte cells relative to each other after day 1 in the individual does were inconsistent and could not give any indication of the stage of the cycle.

\section{CONCLUSION}

The pattern of vaginal cell exfoliation of pubertal cycling WAD does is similar to those reported for other breeds of goats. Non-descript does show an EVC that is compatible with the anoestrus goats. Even though both leucocyte and epithelial cells were present in the smears of the WAD does throughout the oestrous cycle period, their relative association and variation could not be used to discern the stages of the cycle. The morphology of the epithelial cells could, however, be used to determine the reproductive status and to some level of accuracy, the stage of the oestrous cycle in the WAD goats, in line with a pattern that is widely known.

\section{REFERENCES}

[1] Dieleman SJ, Bevers MM, Van Tol HTM, Willemse AH. Perpheral plasma concentrations of oestradiol, progesterone, cortisol, $\mathrm{LH}$ and prolactin during the oestrous cycle in the cow, with emphasis on the peri-oestrous period. Anim Reprod Sci 1986, 10: 275-292.
[2] Perez-Martinez M, Mendoza ME, Romano MC. Exfoliative vaginal cytology and plasma levels of estrone and estradiol-17 $\beta$ in young and adult goats. Small Rumin Res 1999, 33: 153-158.

[3] Lafi SQ, Khamas WA, Hailat NQ, Al-Darraji AM, Fathalla MA. Vaginal cytology in small ruminants. Indian Vet J 1997, 74: 662-665.

[4] Larsen B, Markovetz AJ, Galask RP. Relationship of vaginal cytology to alterations of the vaginal microflora of rats during the estrous cycle. Appl Environ Microbiol 1977, 33: 556-562.

[5] Olson PN, Johnson CA. Vaginal cytology II: Its use in diagnosis and treatment of chronic vaginitis and other reproductive disorders in the bitch. Am J Vet Res 1984, 6: 385-390.

[6] Schutte AP. Canine vaginal cytology-I. Technique and cytological morphology. J Small Anim Pract 1967, 18: 301-306.

[7] National Research Council (NRC). Microgoats. In: Microlivestock - Litle known small animals with a promising economic future. National Academy Press, Washington, DC, 1991, p 32-45.

[8] Akusu MO. Ovarian activities and reproductive potentials of the West African dwarf goat in Ibadan. $\mathrm{PhD}$ thesis in the Department of Veterinary Surgery and Reproduction, University of Ibadan, Ibadan, Nigeria 1987, p 210.

[9] Parer JT. Vaginal content and rectal temperature during the oestrous cycle of the African dwarf goat. Am J Vet Res 1963, 24: 1223-1225.

[10] Colorado State University (CSU). Classification of vaginal epithelial cells. Available from URL: http://arbl.cvmbs.colostate.edu/hbooks/ pathphys/reprod/index.html, (Consulted: September 2004).

[11] SigmaPlot, Exact graph for exact science, version 6.1. SPSS Science, 2000 edition.

[12] Statistical Analysis System (SAS), SAS Inc, Carry, North Carolina, 2000 edition.

[13] Prasad SP, Bhattacharrya NK. Oestrus cycle behaviour in different seasons in Barbari nannies. Indian J Anim Sci 1979, 49: 1058-1062.

[14] Hafez ESE. Reproductive cycles. In: Hafez ESE (Ed), Reproduction in farm animals, Lea and Ferbiger, Philadelphia, 1987, p 116.

[15] Egbunike GN, Ola SI. Efficacy of Progestagen injection for oestrus synchronisation in West African dwarf doe. Proceedings of IX World Congress of Animal Production, 26 - 31 October 2003, Porto Alegre, Brazil, 2003, p 213.

[16] Banumathi T, Mukherjee TK. Oestrous cycle and associated phenomena in Katjang goats. Malaysian Vet J 1981, 7: 58-63. 